\title{
Formulation of Nutritionally Superior and Low Cost Seaweed Based Soup Mix Powder
}

\author{
Jayasinghe PS ${ }^{1 *}$, Pahalawattaarachchi $\mathbf{V}^{1}$ and Ranaweera KKDS ${ }^{2}$ \\ ${ }^{1}$ National Aquatic Resource Research and Development Agency, Crow Island, Colombo, Srilanka \\ ${ }^{2}$ Faculty of Food science, University of Sri Jayewardenepura, Nugegoda, Srilanka
}

\begin{abstract}
The demand for dried instant soups is increasing to their ease of use. In particular, the boom in healthy and functional foods, there is general preference for healthy soup prepared using vegetables, legumes, cereals and mushrooms. Dried instant soup has long shelf life because it is a dried food and frequently has its effective tasting time period set for a relatively long time. This study was conducted to develop a nutritious instant vegetable soup mixture incorporated with cereals, legumes and seaweed extracts such as agar or carrageenan use and was to replace of pectin. The agar and carrageenan area industrial food substitute enrich with protein, minerals, vitamins and amino acid which improve the overall nutritive values and viscosity of the soup. Organoleptic evaluation was conducted to select best combination of ingredients of vegetables, cereals, legumes and preservatives. In addition to that Ulva powder and seaweed extracts (agar or carrageenan) were incorporated in different percentages and was evaluated for the sensory attributes to optimize and compare physical chemical and sensory parameters with commercial vegetable soup mixture. The data rank some test revealed that best soup mixture were evaluated by sensory attributes one commercial available and two formulated soup mixtures with contain $80 \%$ vegetables, $10 \%$ grain, $3.5 \%$ legumes, $2.5 \%$ dried Ulva powder with $3 \%$ agar agar or $2 \%$ carrageenan and preservatives. The soup formulas have highest viscosity (698 cps, $766 \mathrm{cps}, 951 \mathrm{cps})$, water activity $(0.618,0.586,0.437)$, crude protein $(9.3 \%, 7.2 \%, 1.7 \%)$, carbohydrate $(64.54 \%, 61.3 \%, 51.32 \%)$, iodine value and $(0.35,0.32,0$ $\mathrm{mg} / \mathrm{l})$ respectively in agaragar incorporated soup, carrageenan incorporated soup and commercial vegetable soup mixture. The total bacterial counts, total fungal counts and water activity were at the acceptable levels for consumption. The low levels of yeast and mould counts were detected in all the samples during the storage period. This two formulated products can be introduced to the commercial market as alternative medicinal heath food.
\end{abstract}

Keywords: Soup mixture; Agar; Carrageen an; Legumes; Dehydrated seaweeds.

\section{Introduction}

Lack of nutrition education leads to wrong choices of food and resultant malnutrition. The Interrelationship between diet, food habits and nutrient deficiency disease have made efforts to investigation of nutritive value of soup mixture and evaluate the properties of sensory, physical, chemical and nutrients. The nutrient content of most of soups available in the market is high in carbohydrate and low in protein. Deficiencies of nutrients are a major global health problem. More than 2 billion people in the world today are estimated to be deficient in key vitamins and minerals, particularly vitamin $\mathrm{A}$, iodine, iron and zinc. Most of these people live in low income countries and are typically belong to poverty line. Micro nutrient deficiencies increase the general risk of infectious diseases because of compromised immune system as well as the risk [1]. Seaweed is known as rich source of protein, vitamins, amino acids and dietary iodine, macro and micro elements, dietary fiber [2]. The main two polysaccharides agar and carrageenan extracted from seaweeds are vicious hydrocolloids which have thickening properties of food. The growing demand in the role of macro micronutrients in optimizing the health in prevention or treatment of disease [3]. The iodine and other essential elements are rare in land plants which are highly abundance in seaweed. Previous studies have shown that iodine content in breast milk of lactating mothers has a strong correlation with the frequency and quantity of seaweed soup consumption [4]. Iodine is an essential macro and micro element required for thyroid hormone synthesis; impart some of its prevention of cardiovascular disease and cancer and other metabolic reactions. Seaweed soup is low cost nutritive sources and supply protein, minerals, vitamins and amino acids to health diet. The vegetable and cereal mixed soups are enriched with high protein [5]. The incorporation of seaweed extract to soup enhances the nutrition requirement of the diet. The combination of those macro and micro elements play important role in mounting immune response and substantially increase the risk of having poor immune responses to infections [6]. These compounds also help to influence adult and child survival as well as educational achievement, child survival and maternal health [7]. Method of preparation and storage of foods often leads to large loss of nutrients thus creating deficiency risk of nutrients. Therefore efforts have been geared towards the study of nutritional composition of market available and prepared soup. There are no scientific data available on nutritional values of Sri Lankan seaweed based soup mixtures. As the formulation and development of nutritious complementary foods from locally and readily available materials have received a lot of attentions, the present research work aimed to prepare and supplement dried vegetarian soup mixtures incorporated with agar or carrageenan (vicious polysaccharide) and evaluating their chemical, physical, rheological and sensory properties to assess the nutritional and technological quality of the resultant mixtures and soups.

\section{Material and Methods}

\section{Preparation of seaweed extracts}

The seaweed varieties Kappaphycus alvarezii, Ulva lactuca,

*Corresponding author: Jayasinghe PS, National Aquatic Resource Research and Development Agency, Crow Island, Colombo 15, Mattakkuliya, Srilanka, Tel: 0718201287; E-mail: pradee_jaya@yahoo.com

Received March 04, 2016; Accepted March 25, 2016; Published April 02, 2016

Citation: Jayasinghe PS, Pahalawattaarachchi V, Ranaweera KKDS (2016) Formulation of Nutritionally Superior and Low Cost Seaweed Based Soup Mix Powder. J Food Process Technol 7: 571. doi:10.4172/2157-7110.1000571

Copyright: (C) 2016 Jayasinghe PS, et al. This is an open-access article distributed under the terms of the Creative Commons Attribution License, which permits unrestricted use, distribution, and reproduction in any medium, provided the original author and source are credited. 
Gracilaria verrucosa were collected from Northeastern (Trincomalle), Southwestern (Unawatuna and Beruwala) coastal areas of Sri Lanka and transported to NARA laboratory in insulated boxes. Ulva lactuca ,Gracilaria verrucosa and Kappaphycus alvarezii species were washed in seawater initially to remove macroscopic epiphytes and sand particles and finally with fresh water to remove adhering salt. The fresh seaweeds were blanched in $95^{\circ} \mathrm{C}$ hot water in 10 minutes and washed in cold water. They were shade dry for four days followed by oven dry at $60^{\circ} \mathrm{C}$ for 12 hours. Then the materials were hand cursed and made as a coarse powder using mixer grinder. The dried grinded powder was stored in $0^{\circ} \mathrm{C}$ until it is used. The Gracilaria verrucosa (agar) and Kappaphycus alvarezii (carrageenan) were used to extract agar with acid treatments [8] and carrageenan with alkaline treatments [9] respectively. The dried grinded Ulva powder, agar and carrageenan were stored in $15^{\circ} \mathrm{C}$ until used.

\section{Preparation of vegetables}

The vegetables pumpkins, carrot, potato, mushrooms, tomato, B-onions, leaks, celery, carrot and cereals, red rice, soya bean, green gram, pepper, salt, corn starch were purchased from super market. Potato carrot and pumpkin samples were sorted, washed, peeled and sliced in cubic form and blanched in hot water at $95^{\circ} \mathrm{C}$ for $5 \mathrm{~min}$, then washed in cold water then hot air flow drying were performed at $65^{\circ} \mathrm{C}$ in the first four hours and then reduced to $50^{\circ} \mathrm{C}$ till completely drying. Then milled and sieved ( 315 micron) into powdered form. Tomatoes were sliced then dried and milled as the above mentioned vegetables; the green gram and soya bean were subjected to some technological treatments as soaking in 1:2 w/v water ratios for 30 minutes, and then cooked for 15 minutes before dried and milled for soup formulation.

\section{Formulation of the dried vegetarian soup mixtures}

The prepared samples were seasoned with dried onion, garlic, coriander, black pepper, cumin salt and agar or carrageenan then mixed to formulate four dried vegetarian soup mixtures (three replicates for each formula) namely $\mathrm{F}_{1}$ andF $_{2}$ as shown in Table 1 . The obtained mixtures were packed into polyethylene bags and kept at $-20^{\circ} \mathrm{C}$ for further analysis. The formula 1 were made using different percentages $4 \%, 3 \%, 2 \%, 1 \%$ of agar agar. The formula 2 were made out using same procedure for different carrageenan percentage $4 \%$,

\begin{tabular}{|c|c|c|}
\hline Ingredients & $\begin{array}{c}\text { Formula } 1 \\
(\mathrm{~g} / 100 \mathrm{~g})\end{array}$ & $\begin{array}{c}\text { Formula } 2 \\
(\mathrm{~g} / 100 \mathrm{~g})\end{array}$ \\
\hline Agar & $3 g$ & \\
\hline Carrageenan & & $2 g$ \\
\hline Ulva powder & 2.5 & 2.5 \\
\hline Tomtato & 5 & 5 \\
\hline Mush room & 3 & 3 \\
\hline Pumpkin & 10 & 10 \\
\hline Carrot & 15 & 15 \\
\hline Green gram & 15 & 15 \\
\hline Curry leaves & 8 & 8 \\
\hline Soya bean & 15 & 15 \\
\hline Red rice & 15 & 15 \\
\hline Garlic & 1 & 1 \\
\hline Salt & 2.5 & 2.5 \\
\hline Black pepper & 1 & 1 \\
\hline Onion & 3 & 3 \\
\hline Citric acid & 0.1 & 0.1 \\
\hline Sodium benzoate & 0.3 & 0.3 \\
\hline
\end{tabular}

Table 1: Formulas of dried vegetarian soup mixtures $(\mathrm{g} / 100 \mathrm{~g})$.
$3 \%, 2 \%, 1 \%$. Organoleptic parameters were measured to obtain of best percentages of agar or carrageenan.

\section{Analysis of chemical parameters}

The chemical, physical parameters were measured: macro and micro, proximate composition, viscosity (Brookfield viscosity meter), water activity (Spring water activity meter), dietary fiber [10], total Plate Count [11]. Standard deviation and variance of means (ANOVA) were calculated using statistical analysis package SPSS14 [12].

\section{Rheological properties of the resultant soup samples}

Rheological parameters (viscosity and shear rate) of dried vegetarian soup samples were measured according to Brookfield manual by using Brookfield viscometer. The sample was placed in a small sample adapter and a constant temperature water bath was used to maintain the desired temperature. The viscometer was operated between 10 and $60 \mathrm{rpm}$. Viscosity and shear rate data were obtained directly from the instruments; the SC4-21 spindle was selected for the measurement. Rheological measurements were made at the resultant soup samples $\left(\mathrm{F}_{1} \mathrm{~F}_{2}\right.$ and $\mathrm{F}_{3}$ commercial soup) at room temperature $\left(25^{\circ} \mathrm{C} \pm 1^{\circ} \mathrm{C}\right)$.

\section{Organoleptic evaluation of the resultant soup samples}

The resultant soup samples were organolyptically evaluated after dissolving in hot water $(25 \mathrm{~g}$ dried vegetarian soup mixtures $/ 250 \mathrm{ml}$ water) for its sensory characteristics, taste, flavor, color, thickness and appearance, dissolution rate and overall acceptability. The evaluation was carried out by using ten panelists according to the method of [13].

\section{Shelf life assessments}

The shelf life were measured for prepared different soup formulas packed in air tight polystyrene packets and stored in three different temperatures, ambient temperature, $0^{\circ} \mathrm{C}$ and $-18^{\circ} \mathrm{C}$ during six month period. Shelf life was determined by measuring of changes of overall acceptability, total bacterial count, total fungal count and water activity monthly over a six month period.

\section{Results and Discussion}

The best composition of selected from formula 1 was recorded for $3 \%$ agar $10 \%$ grains, $80 \%$ vegetables $2.5 \%$ Ulva powder and $10 \%$ legumes and other ingredients. The procedures followed in formula 2 which was formulated with carrageenan $2 \%$ are with other ingredients were selected as best composition. The viscosity of soup mixtures was lower than that of commercial available market soup sample. The viscosity level both the soup mixture was improved to market standards by incorporation of dried Ulva species powder and corn starch. This increased in the apparent viscosity of the formulated soup closer to the commercial sample.

\section{Viscosity of the resultant soup samples}

The physical properties of soup mixture were dramatically improved by incorporate of agar agar and Carrageenan. The highest apparent viscosity was found at commercial sample $951 \mathrm{cps}$ followed by formula 2 and formula1. The significant variation could be observed among commercial sample and formula 1 and 2 . Soup mixture commonly available market contains corn starch as thickening agent. The formulated soup shows the potential application of agar or carrageenan as a viscosity enhancer. Agar is generally water- soluble and very hydrophilic. The agar with low gelling property products provides the semi-solid body and high viscosity to the soup preparation. In high 
gel strength agar can be added limited amount as liquid thickener or viscose's media. In soup preparation, viscosity is an index of thickness [14]. Carrageenan or agar is used as thickening agents in food to provide the desirable viscosity to the soup mix [15]. $\beta$-glucan has a lower or equal ability to increase viscosity as xanthan, guar gum, locust bean gum and Arabic gum. The good viscosity forming properties make $\beta$-glucans potential alternatives as thickening agents in different food applications [16]. The functional properties of pulse proteins play an important role in food formulation and processing.

The relationship between shear rate (S) and values of the viscosity (cps) of the dried vegetarian soup supplemented with carrageenan agar and commercial sample given in Figure 1. It seems that the apparent viscosity (cps) of soup samples decreased as shear rate increased. This simply means that the three dried vegetarian soups F1 and F2 had a noticeable apparent viscosity pattern which could be characterized within the non-Newtonian pseudo plastic flow behavior [17]. The same Figure depicts that apparent viscosity pattern recorded the highest value compared to F1and F2, it decreased sharply while; apparent viscosity patterns in and F1 and F2 were much closer to each other and decreased gradually. The high viscosity pattern of F3 could be due to the higher proportion and the functionalities of corn flour starch and its $\beta$-glucan. The reduction of apparent viscosity pattern of F1 and F2 may be due to the reduced proportion of agar or carrageenan during formulation.

There were no observed significant changes in water activity levels of three different formulas. The water activity content was less than the 0.6 and it range from $0.564 \pm 0.4$ to $0.597 \pm 0.8$. The low level of water activity content may have restricted the growth rate of microorganisms. Almost all microbial activity is inhibited below aw 0.6 [18]. while between most fungi are inhibited below $\mathrm{a}_{\mathrm{w}} 0.7$, most yeast are inhibited below aw 0.8 and most bacterial growth below aw 0.9 [18]. Very low values of aw are related to high lipid oxidation rates. $A_{w}$ values of 0.2 and 0.4 lipids have been suggested to have optimal stability and oxidation rates increase with increasing aw [19]. According to the present study (Table 2) initial levels of microorganisms in tested samples were comparatively lower and in the range of $1 \times 10^{2}$ to $2 \times$ $10^{2}$. All the three samples were much lower compared to the maximum allowable limits. The product can be stored for further period of time.

\section{Sensory attributes of different type of soup mixtures}

Sensory evaluation considered to be a valuable tool in solving problems involving food acceptability. It is useful in product improvement, quality maintained and more important in new product development. It is desirable that the product to free from off flavors',

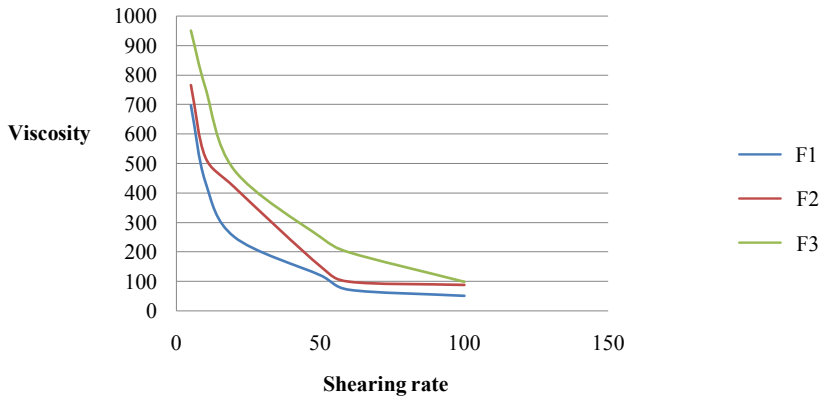

F1-agar incorporated soup mixture, F2-Carrageenan incorporated soup mixture, F3-Commercial product.

Figure 1: Viscosity of three different soup mixtures at different shearing rates.

\begin{tabular}{|c|c|c|c|}
\hline $\begin{array}{c}\text { Macro and } \\
\text { Micro Elements } \\
\mathbf{m g} / \mathbf{1 0 0 g}\end{array}$ & Formula 1 & Formula 11 & Market soup \\
\hline Cobalt (Co) & $\mathrm{ND}$ & $\mathrm{ND}$ & $\mathrm{ND}$ \\
\hline $\mathrm{Ni}$ & $\mathrm{ND}$ & $\mathrm{ND}$ & $\mathrm{ND}$ \\
\hline $\mathrm{Cr}$ & $\mathrm{ND}$ & $0.08 \pm 0.86$ & $1.3 \pm 0.7$ \\
\hline $\mathrm{Mn}$ & $\mathrm{ND}$ & $1.97 .0 \pm 0.45$ & $1.2 \pm 0.31$ \\
\hline $\mathrm{K}$ & $53.39 \pm 0.07$ & $98 \pm 0.42$ & $5.6 \pm 0.45$ \\
\hline $\mathrm{Mg}$ & $45.8 \pm 0.98$ & $54.9 \pm 0.23$ & $4.9 \pm 0.32$ \\
\hline $\mathrm{Ca}$ & $250.56 \pm 0.75$ & $125.9 \pm 0.21$ & $3.8 \pm 0.23$ \\
\hline $\mathrm{Na}$ & $115.76 \pm 0.56$ & $126.8 \pm 0.32$ & $5.3 \pm 0.12$ \\
\hline lodine & $0.62 \pm 0.02$ & $0.75 \pm 0.02$ & 0 \\
\hline
\end{tabular}

Table 2: Comparison of mineral content of in different soup formula powder mixtures.

unacceptable aroma and faulty texture. The market sample was also observed to be in highest sensory quality. Formula 1 and 2 showed same points for sensory quality. Table 3 indicates the sensory quality attributes of resultant soup thickener with different soup mixtures. Incorporation of agar and carrageenan significantly affected thickness as well as dissolution rate. Sensory studies showed that all three samples were not significantly difference in appearance, color, texture, aroma, taste and overall acceptability. The commercial sample is used with corn starch as thickening agent in $\beta$-glucane. Therefore agar or carrageenan can be successfully substituted to corn starch as a thickener with higher level of sensory acceptability.

\section{Proximate composition of dry vegetable soup mixtures}

The proximate composition of the different soup formulas were given in Table 4 . The highest protein values were observed in the formula 1 followed by formula 2 and commercial vegetable soup sample. There were significant differences between protein content of commercial sample, F1 and F2 soup formulas. The protein content ranged from 1.7-11.3. There were no significant difference between F1 and F2. The soya bean, cow pea and added seaweed polysaccharides enhance the protein content in soup formula 1 and 2 . The present data is similar to the observations of [20] who mention that legumes and seaweed are high in protein and especially rich in lysine and leucine, low in fat and excellent source of dietary fiber and complex carbohydrate.

The highest oil content $2.68 \%$ was observed at market soup samples followed by formula 1 and 2 . There was no statistical difference among oil contents of soup formulas. The fat content ranged from $2.3 \%-2.68 \%$ at different soup formulas. Agar and carrageenan have low oil content [21]. The results of present study confirm the observations of Amal et al. [17] Observed similar oil contents in the diets from dried vegetable soup mixture. The highest carbohydrate content was also observed at formula 1 than in others soups. It can be concluded that formula 1 has the highest nutritional compounds than other two formulas. The soup mixture formula 1 supply highest carbohydrate content followed by formula 2 and then commercial soup sample. The carbohydrate content is over $60 \%$ in all seaweed polysaccharides. The application of these polysaccharides stabilized the food product against degradation. These polysaccharides enhance acceptability and shelf life [22]. The ash content is an indicator of minerals. Seaweed is rich source of minerals. The highest ash content was recorded in formula 2 followed by formula 1 and market soup. Dietary sources of essential elements are important for correct physiological functions of human body. A Deficient intake of certain minerals can produce diseases and lead to abnormal development [23].

The availability of macro and micro elements were observed in 


\begin{tabular}{|c|c|c|c|c|c|c|c|}
\hline $\begin{array}{l}\text { Different soup } \\
\text { Formulas }\end{array}$ & $\begin{array}{l}\text { Taste (10) } \\
\text { Mean } \pm \text { SE }\end{array}$ & $\begin{array}{l}\text { Colour (10) } \\
\text { Mean } \pm \text { SE }\end{array}$ & $\begin{array}{c}\text { Flavour }(10) \\
\text { Mean } \pm \text { SE }\end{array}$ & $\begin{array}{c}\text { Thickness } \\
\text { Mean }(10) \pm \text { SE }\end{array}$ & $\begin{array}{c}\text { Dissolution rate (10) } \\
\text { Mean } \pm \text { SE }\end{array}$ & $\begin{array}{c}\text { Overall acceptability (50) } \\
\text { Mean } \pm \text { SE }\end{array}$ & Colors \\
\hline Formulas 1 & $8.3 \pm 1.7$ & $9.4 \pm 1.23$ & $8.6 \pm 1.2$ & $8.55 \pm 1.27$ & $8.45 \pm 0.3$ & $43.3 \pm 1.14$ & Orange yellow \\
\hline Formulas 2 & $8.4 \pm .25$ & $9.45 \pm 1.54$ & $8.4 \pm 1.53$ & $8.63 \pm 1.6$ & $8.9 \pm 1.6$ & $43.78 \pm 1.8$ & Orange Yellow \\
\hline $\begin{array}{l}\text { Market available } \\
\text { sample }\end{array}$ & $9.10 \pm 1.67$ & $8.50 \pm 1.32$ & $9.1 \pm 1.67$ & $9.0 \pm 1.9$ & $9.1 \pm 1.6$ & $44.8 \pm 1.63$ & Yellow \\
\hline
\end{tabular}

Table 3: Comparison of sensory attributes of different soup formulas (Mean $\pm \mathrm{SE}$ ).

\begin{tabular}{|c|c|c|c|}
\hline Parameters & Formula 1 & Formula 11 & commercial soup sample \\
\hline Protein (\%) & $11.3 \pm 0.8$ & $11.2 \pm 0.6$ & $1.7 \pm 0.4$ \\
\hline Oil (\%) & $2.4 \pm 0.7$ & $2.3 \pm 0.6$ & $2.68 \pm 0.5$ \\
\hline Carbohydrate (\%) & $64.54 \pm 0.4$ & $61.34 \pm 0.5$ & $51.32 \pm 0.5$ \\
\hline Moisture content (\%) & $12.6 \pm 0.4$ & $12.3 \pm 0.6$ & $14.5 \pm 0.5$ \\
\hline Ash (\%) & $9.5 \pm 0.3$ & $9.7 \pm 0.3$ & $9.3 \pm 0.2$ \\
\hline TPC (Total Plate Count) & $1 \times 10^{2} \pm 0.1$ & $2 \times 10^{2} \pm 0.54$ & $1 \times 10^{3} \pm 0.65$ \\
\hline
\end{tabular}

Table 4: Comparison of proximate composition and TPC (Total Plate Count) in different soup formulas (dry weight basis, mean \pm SE).

\begin{tabular}{|c|c|c|c|}
\hline Parameters & Formula 1 & Formula 2 & $\begin{array}{c}\text { Commercial soup } \\
\text { sample }\end{array}$ \\
\hline viscosity (cp) & $698 \pm 0.3$ & $766 \pm 0.5$ & $951 \pm 0.5$ \\
\hline $\begin{array}{c}\text { Overall } \\
\text { acceptability }\end{array}$ & $8 \pm 0.2$ & $8 \pm 0.3$ & $10 \pm 0.6$ \\
\hline water activity & $0.564 \pm 0.4$ & $0.505 \pm 0.6$ & $0.597 \pm 0.8$ \\
\hline pH & $6.3 \pm 0.5$ & $6.7 \pm 0.8$ & $6.9 \pm 0.2$ \\
\hline
\end{tabular}

Table 5: Comparison of physical and sensory attributes of laboratory prepared soup and commercial soup samples (Mean \pm SE).

Table 2 in three different soup Formulas. The availability of $\mathrm{Ca}, \mathrm{Na}, \mathrm{Mg}$ and $\mathrm{K}$ values were significantly very high in laboratory prepared two soup samples than in commercial samples.

The significantly $(\mathrm{P}<0.05)$ highest $\mathrm{Ca}$ content was found in formula $1(250.056 \mathrm{mg} / 100 \mathrm{~g})$ followed by formula $2(125.9 \mathrm{mg} / 100 \mathrm{~g})$. The lowest value was found in commercial sample $(3.8 \mathrm{mg} / 100 \mathrm{~g})$. The differences among the $\mathrm{Ca}$ content of samples were due to the high $\mathrm{Ca}$ availability of agar which was extracted from the red algae. These very high Ca content seaweed soup consumption may be useful in case of expectant mothers elderly and adolescents that all expose to risk of $\mathrm{Ca}$ deficiency [24]. Most of the vegetable soups in the market have low levels but not sufficient to meet adequate intake of calcium for adult $1000-1200 \mathrm{mg} /$ day. Calcium deficiency is certainly a risk factor for osteoporosis in later life [25].

The Table 5 showed the Na content in dry soup formulas. The significantly highest value $(126.8 \mathrm{mg} / 100 \mathrm{~g})$ was found in formula 11 followed by formula $1(115.76 \mathrm{mg} / 100 \mathrm{~g})$. The lowest value was observed in commercial market soup samples. The $\mathrm{Na}$ contents were ranged from 5.3 to $126.86 \mathrm{mg} / 100 \mathrm{~g}$. Sodium is the major positive ion in the extracellular fluid and key factor in retaining body water. Under the FDA food-labeling rules, the daily value for sodium is $2400 \mathrm{mg}$. Two soups prepared in the laboratory were within the RDA (Recommended Daily intake for Adult) [26]. The highest macro and micro elements were observed in formula 2 where average $\mathrm{K}$ content was $98 \pm 0.42$ $\mathrm{mg} / 100 \mathrm{~g}$. The macro elements in formula 2 were three times higher than that of formula 1 . The metals in both two soup formulas were significantly higher than that of market soup samples. This is due to highest availability of minerals in seaweeds than in land plants. Potassium plays a similar role with sodium in the biological system. But it is located in the intracellular fluids. Unlike sodium it is associated with lower levels rather than higher blood pressure values [6].

The Mg content was found significantly highest $(45.8 \pm 0.98)$ in formula 1 followed by formula 2 in $54.9 \pm 0.23$. The lowest $\mathrm{Mg}$ content

was observed in market soup sample [27]. The very low Mg content found in market sample in the present study may be due to the unavailability of $\mathrm{Mg}$ found in land plants compared to $\mathrm{Mg}$ content of agar extracted from red seaweed. The variation between formula 1 and formulae 11 may be attributes to red seaweed species extracted agar and carrageenan and differences their habitats and metabolic preferences.

The whole samples were with free or low amount was observed in the toxic elements such as $\mathrm{Co}, \mathrm{Ni}$, and $\mathrm{Cr}$. This formula 1 and 2 were observed as nutritionally rich source for healthy life of children's and pregnant mothers. The iodine content was found zero in commercial vegetable soup while it ranged $0.7-0.6 \mathrm{mg} / 100 \mathrm{~g}$ in a laboratory prepared soup mixtures. For people with lower organ functions and greater need of optimization of body iodine stores intakes up to $50 \mathrm{mg}$ per day can be use safety [28]. Brown seaweeds are the main source of iodine treated for thyroid conversely, getting sufficient iodine seems to protect against this disease [29].

From the above nutritional data, it could be demonstrated that the dried vegetarian soup mixture had reasonable amount of required nutrients particularly protein, energy, fats, ash and micro elements.

\section{Shelf life assessments}

In $\left(-18^{\circ} \mathrm{C}\right)$ deep freezer stored samples were found to have overall acceptability 9 (very much like) score from initially to until six month of storage [30-34]. The slight increase of microbial growth was observed after four months and finally it was $3 \mathrm{cfu} / \mathrm{g}$. There were no significant difference observed in all the parameters during six month period storage at $-18^{\circ} \mathrm{C}$. In storage of $0^{\circ} \mathrm{C}$ (freezer) was found significant difference from $3^{\text {rd }}$ month to six month in all three parameters analyzed were range 9-7, 1-90 cfu/g, 2-4 cfu/g respectively (Table 6). Overall acceptability, TBC and TFC. Dramatically increased in $27^{\circ} \mathrm{C}$ sample stored over months. The results show positive correlation of microbial growth and deterioration in sensory quality. The reduction of sensory quality may be due to the slight increase of microbial and fungal growth. The shelf life of $\left(-18^{\circ} \mathrm{C}\right)$ deep freezer stored samples can be estimated more than six month. While freezer storage $\left(0^{\circ} \mathrm{C}\right)$ samples can be kept five to six month without deterioration [35-37]. The samples stored in ambient temperature have short shelf life around three months.

\section{Conclusion}

The two seaweed extracts of carrageen and agar were identified as potential nutritive thickener and gelling agent in the soup industry. The small quantity of agar and carrageenan improved apparent viscosity 


\begin{tabular}{|c|c|c|c|c|c|c|c|c|c|}
\hline \multirow[t]{2}{*}{ Parameters } & \multicolumn{3}{|c|}{$-18^{\circ} \mathrm{C}$ storage (Deep freezer) } & \multicolumn{3}{|c|}{$0^{\circ} \mathrm{C}$ storage (Freezer) } & \multicolumn{3}{|c|}{$27^{\circ} \mathrm{C}$ storage (ambient temperature) } \\
\hline & Initial & $3^{\text {rd }}$ month & Final & Initial & $3^{\text {rd }}$ Month & Final & Initial & $3^{\text {rd }}$ month & Final \\
\hline Overall acceptability & $9 \pm 0.56$ & $9 \pm 0.56$ & $9 \pm 0.56$ & $9 \pm 0.56$ & $8 \pm 0.43$ & $7 \pm 0.26$ & $9 \pm 0.78$ & $8 \pm 0.45$ & $6 \pm 9.34$ \\
\hline Total bacterial count (cfu/g) & $1 \pm 1.3$ & $1 \pm 1,8$ & $3 \pm 1,8$ & $1 \pm 1.3$ & $3 \pm 1 . .8$ & $90 \pm 12$ & $1 \pm 0.23$ & $306.8 \pm$ & $900 \pm 24.9$ \\
\hline Total fungal count, (cfu/g) & $2 \pm 0.23$ & $1 \pm 0.2$ & $2 \pm 0.05$ & $2 \pm 0.05$ & $4 \pm 0.8$ & $8 \pm 1.7$ & $2 \pm 0.4$ & $4 \pm 0.3$ & $8 \pm 2$ \\
\hline Water activity $\left(\mathrm{A}_{\mathrm{w}}\right)$ & $0.54 \pm 0.066$ & $0.54 \pm 0.024$ & $0.6 \pm 0.034$ & $0.54 \pm 0.056$ & $0.6 \pm 0.075$ & $0.67 \pm 0.056$ & $0.54 \pm 0.075$ & $0.73 \pm 0.076$ & $0.73 \pm 0.087$ \\
\hline
\end{tabular}

Table 6: Effect on storage conditions six month duration on sensory and microbial quality of soup formula 1 (Mean \pm SE).

value of the product considerably. But we can use limited amount of agar or Carrageenan for development of thickness of soup. The higher proportions of agar or carrageenan may induce to set into a gel in room temperature. It can be concluded that trace metal composition of improved seaweed base soup mixture is five times higher than that of commercially available vegetable soup mixture. The iodine values of the seaweed based soup formulas were higher than the commercial vegetable soup mixture in the available. The iodine level of the seaweed based soup mixtures supply the iodine requirement of thyroid. This soup can be recommended as therapeutic food for dietary iodine and mineral deficiencies. The experiments on two soup products stored in polystyrene packets was expired in three months duration in ambient temperature whereas more than six month in deep freezer and six months duration in freezer storage.

\section{References}

1. The World Health Report (2001) Reducing risks, promoting healthy life. World Health Organization, Geneva.

2. Matsuzaki S, Iwamura K (2001) Application of seaweeds to human nutrition and medicine. Nahrungausdem Meer, Food from the sea. Springer, New York.

3. Field CJ, Johnson IR, Schley PD (2002) Nutrients and their role in host resistance to infection. J Leukoc Biol 71: 16-32.

4. Zava TT, Zava DT (2011) Assessment of Japanese iodine intake based on seaweed consumption in Japan: A literature-based analysis. Thyroid Res 4: $14-19$

5. Tilakaratne BM (2013) Formulation of nutritionally superior and cost cereal based soup mix powder using source of protein. Institute of Post-harvest Technology, Anuradapura.

6. Walker A (2000) Micronutrients and infections: an African perspective. Nutrition 16: $1096-1097$

7. FSAU (2005) Micronutrients for healthy, happy families: Micronutrients in Somalia. FSAU/FAO, Kenya.

8. SOP/AP/001/(2003) Standard operation procedure, Determination of agar properties, agar yield, gel strength, ash content and clarity, gelation and melting points, sulphate content and moisture content. MSM Project Management Services Private Limited, Chennai, India.

9. Anon (2011) Researches urge awareness of dietary iodine intake in postpartum Korean American women who consume brown seaweed soup. Science News.

10. AOAC (1984) Official methods of analysis. Washington DC. Association of Official Analytical Chemists.

11. Busta F (1984) Colony count method. Compendium of method for microbiological examination of food.

12. SPSS 14 (2007) Bio-statistical analysis software package.

13. Kaplan BJ, Crawford SG, Field CJ, Simpson JS (2007) Vitamins, minerals, and mood. Psychol Bull 133: 747-760.

14. Ikegwu OJ, Oledinma NU, Nwobasi VN, Alaka IC (2009) Effect of Processing Time and Some Additiveson the Apparent Viscosity of "Achi" Brachystegiaeurycoma Flour. Journal of Food Technology 7: 34-37.

15. Abeysinghe CP, Illepruma CK (2006) Formulation of an MSG (Monosodium Glutamate) free instant vegetable soup mix. Journal of the National Science Foundation of Sri Lanka 34: 91-95.
16. Lyly M, Salmenkallio-Marttila M, Suortti T, Autio K, Poutanen K, et al. (2004) The sensory characteristics and rheological properties of soups containing oat and barley B-Glucan before and after Freezing. LWT-Food Science and Technology 37: 749-761.

17. Amal MH, Abdel-Haleem, Azza AO (2014) Preparation of dried vegetarian soup supplemented with some legumes. Food and Nutrition Science, 2014, 5, 2274-2285.

18. Garcia JM, Chambers E, Matt Z, Clark M (2005) Viscosity measurement of nectar and honey thick liquid: product, liquid, and time comparisons. Communication Sciences \& Disorders, School of Family Studies \& Human Services, Kansas State University, Manhattan, Kansas, Dysphaga 20: 325-335.

19. Raitio R, Orlien V, Skibsted LH (2011) Storage stability of cauliflower soup powder: The effect of lipid oxidation and protein degradation reactions. Food Chem 128: 371-379.

20. Micale Donaldson (2011) Recent advance in iodine nutrition.

21. Luo YW, Xie WH, Cui QX (2010) Effects of phytase, cellulase, and dehulling treatments on iron and zinc in vitro solubility in faba bean (Vicia faba L.) Flour and Legume Fractions. J Agric Food Chem 58: 2483-2490.

22. Subba Rao PV, Vaibhave AM, Gunasena K (2011) Mineral composition of edible seaweeds Porphyra vietnamensis. Food Chemistry 102: 215-218.

23. Fellows $P$ (2000) Food processing technology principles and practice. Wood head Publishing Limited and CRC Press LLC, Washington DC.

24. Burtin $P$ (2003) Nutritional value of seaweeds. Elec J Environ Agric Food Chem. 25. Nan F (2011) Your thyroid may be hungry for some seaweed.

26. Greely A (1997) A pinch of controversy shakes up dietary salt. FDA consumer

27. Wang R, Zhang M, Mujumdar AS, Sun JC (2009) Microwave Freeze-Drying Characteristics and SensoryQuality of Instant Vegetable Soup. Drying Technology 27: 962-968.

28. Istin Sri, Masao ohno, Hirozakusunose (1994) Methods of analysis for aga carrageenan and alginates in seaweeds. Bull Mar Sci Fish, Kochin University, India.

29. Jayasinghe PS, Pahalawattaarachchi V, Ranaweera KKDS (2011) Chemica composition of six edible seaweed species available in Sri Lanka. Proceedings of Annual sessions of National Aquatic Resource Research and Development Agency.

30. Hurtado AQ (2005) Socio-economic impact of epiphytes on the farming and trading of Kappaphycus and processing of Carrageenan (Terminal report)

31. Tadao T (1992) Seaweed, their chemistry and uses, Science of Processing Marine Food Products. Kanagawa International Fisheries Training Centre Japan International Agency, Japan.

32. Fellows P (2000) Food processing technology principles and practice. Woodhead Publishing Limited and CRC Press LLC, Washington DC.

33. Wardlaw GN (1999) Perspective in nutrition. McGraw- Hills, Boston

34. García-Pascual P, Sanjuán N, Melis R, Mulet A (2006) Morchella esculenta (Morel) Rehydration Process, Modeling. Journal of Food Engineering 72: 346-353.

35. Padua MD, Fontoura PSG, Mathias AB (2004) Chemical composition of Ulvaria oxysperma (kutzing) Bliding, Ulvalactuca (Linnaeus) and Ulvafascita (Delile) Barazilian Archives of B iology and Technology 47: 49-55.

36. Allen LH (2001) Micronutrients 2020 focus 5 - Health and nutrition emerging and reemerging issues in developing countries.

37. Adsule RN (1996) Food and feed from legumes and oil seeds. Food and feed from legumes and oil seeds, Chapman and Hall Publisher, London. 